\title{
Biodiversity centre stage
}

\author{
The IPBES global assessment has brought biodiversity prominently to the attention of policymakers and the public, \\ and researchers should seize this critical opportunity to engender change towards sustainability.
}

ew readers of this journal will have missed the recent release of the Intergovernmental SciencePolicy Platform on Biodiversity and Ecosystem Services (IPBES)'s summary for policymakers (https://www.ipbes. net/sites/default/files/downloads/ spm_unedited_advance_for_posting_htn. pdf), a 39-page prelude to the release of the full 1,500-page report later this year. The culmination of 3 years of systematic review by hundreds of experts, the report is the first intergovernmental assessment of biodiversity, its contributions to humanity and scenarios for its protection. The four sections of the report cover the decline in biodiversity and ecosystem services, the accelerating drivers of this change, the failure to meet many of the goals set for conservation and sustainability and the transformative change needed to rise to the challenge. Key billing in both the report and the media coverage was given to the role of food, particularly in terms of terrestrial land use and fishing in the oceans.

The substantial media attention received by the report is to be welcomed. Never before has global biodiversity, as opposed to a specific species or ecosystem, been discussed to this extent. This is partly because, being the result of intergovernmental dialogue, the potential for policy action is genuine. The IPBES's commendable media outreach efforts have also been rewarded. And there has been an undeniable influence of a 'perfect storm' of environmental awareness. The campaigning of Greta Thunberg, Netflix's David Attenborough documentary, the actions of Extinction Rebellion, the EATLancet sustainable diet recommendations (Tuomisto, H. L. Nat. Ecol. Evol. 3, 720-721; 2019) and the call for a Green New Deal in the United States by Alexandria OcasioCortez and Edward J. Markey have all helped to make parts of the public receptive to reading about the IPBES report.

Raising the political profile of biodiversity will inevitably provoke new naysayers. The climate community, whose prominent Intergovernmental Panel on Climate Change (IPCC) is the model for IPBES, has long been the target of out-andout deniers who argue against the science itself. So far, the biodiversity community has more often faced obfuscation and sidelining, but direct attacks on the science may become more common. For example, the British journalist Toby Young disputed (https://www.spectator.co.uk/2019/05/ the-uns-extinction-warning-doesntadd-up/) one of the headline figures from the report, that 1 million species face extinction. Fortunately, one of the authors of the IPBES report, Andy Purvis, used Twitter to counter these arguments (https://twitter.com/AndyPurvisNHM/ status/1126407671463256064). However, the criticisms do raise two concerns about how the IPBES report was released. One is whether it was wise to release the policymaker summary before the full report, even though there were good logistical reasons to do so, as this allowed commentators like Young to claim a lack of transparency. The other is whether more effort could have been made to avoid the 1 million species figure becoming the main focus of discussion, whereas figures with less uncertainty surrounding them, such as those on habitat loss and population decline, are arguably more important. That said, for those without a vested interest in disbelieving the report, the 1 million species figure is a prominent mnemonic comparable to the $1.5^{\circ} \mathrm{C}$ in the 2018 IPCC report.

Another key message that has arisen from media coverage of the report is that biodiversity deserves as much attention and concern as climate. Indeed, this was part of the philosophy behind the establishment of the IPBES as a counterpart to the IPCC. But to many scientists, this is a false dichotomy. Climate and biodiversity, and the crises we face in each case, are linked. Many of the ecosystem services provided by biodiversity relate to climate, and climate change will threaten biodiversity to an increasing extent over the coming decades. However, given that the main focus in public discourse on the climate crisis is on energy and emissions, the IPBES report's main focus on food and land use will hopefully broaden the spectrum of environmental awareness, with benefits for both biodiversity and climate.

Although most readers will be well aware of the report, many may not yet have had time to read the full policymaker summary.
We strongly encourage our readers to do so as it is a powerful and wide-ranging summary of what every scientist needs to know when discussing biodiversity with policymakers and the public. As well as the widely reported findings on trends and drivers of biodiversity loss, there is a substantial focus on the transformative social and political change required to counter this. Other notable but less reported aspects are the importance of land management by indigenous groups, the significance of evolution when predicting biodiversity trends, the effects of international trade and infrastructure expansion and the role of cities in creating sustainable solutions. The report also details the importance of biodiversity for all of the United Nations' Sustainable Development Goals.

So, how should the ecology and evolution community move forward in light of the report, capitalising on the attention it has garnered? 'Keep up the good work' is the somewhat trite response - it is the meticulous research carried out by scientists that backs up every statement in the report and will continue to do so in future reports. But there is also an opportunity to reach out a bit further. The broad scope of the report makes it clear that it is not just scientists working explicitly on biodiversity declines who have a role. Those working on evolutionary processes, or phylogenetic diversity, or fundamental ecology, for example, all have the opportunity to make the connection between their work and the importance of biodiversity when talking to the press or the public. Moreover, the report is very clear about the level of transformative change required to achieve sustainability. As citizens, we have an obligation to engage with our politicians about this, but as experts, we have the potential to make this engagement deeper and more compelling. If we all spent a few minutes sending our own lay summary of the report to our nearest and most relevant political representatives and asking what they are going to do about it, that would be a good start.

Published online: 17 May 2019

https://doi.org/10.1038/s41559-019-0922-2 